\title{
Properties of sludge generated by the treatment of fluoride- containing wastewater with dicalcium phosphate dihydrate
}

\author{
Masamoto Tafu $^{1} \cdot$ Yuki Arioka $^{2} \cdot$ Saori Takamatsu $^{1} \cdot$ Takeshi Toshima $^{3}$
}

Received: 11 February 2016/Accepted: 25 August 2016/Published online: 12 September 2016

(C) Springer International Publishing Switzerland 2016

\begin{abstract}
Fluoride-containing wastewater is discharged from various industrial sites, including semiconductor, plating, and metal-treatment plants. To remove the fluoride, we treated wastewater with dicalcium phosphate dihydrate (DCPD, $\mathrm{CaHPO}_{4} \cdot 2 \mathrm{H}_{2} \mathrm{O}$ ) to form fluorapatite $\left[\mathrm{Ca}_{10}\left(\mathrm{PO}_{4}\right)_{6} \mathrm{~F}_{2}\right]$ crystals. We investigated the fluoride removal efficiency and the properties of the resulting sludge. For comparison, we also treated wastewater using conventional aluminum coprecipitation. The DCPD used in this study was a by-product of the gelatin industry. Nanoscale precursor particles were induced on the DCPD by treatment with warm water. After treatment of fluoridecontaining wastewater in batch experiments, the amount, particle size distribution, settleability, and filterability of the resulting sludge were measured to assess the usability of DCPD. We found that the amount of chemical additives required for the DCPD method was less than that for the conventional method. Additionally, the amount of sludge produced using the DCPD method was small and the final fluoride concentration was below $5 \mathrm{mg} \mathrm{L}^{-1}$. In settleability tests, the sludge produced by the DCPD method was precipitated within $10 \mathrm{~min}$. In filterability tests, most DCPD sludge was separated within $5 \mathrm{~min}$. The settleability and
\end{abstract}

Masamoto Tafu

tafu@nc-toyama.ac.jp

1 Department of Applied Chemistry and Chemical Engineering, National Institute of Technology, Toyama College, 13 Hongo-machi, Toyama 939-8630, Japan

2 Master's Program in Life Science Innovation, University of Tsukuba, 1-1-1 Tennoudai, Tsukuba, Ibaraki 305-8577, Japan

3 Department of Mechanical Engineering, National Institute of Technology, Toyama College, 13 Hongo-machi,

Toyama 939-8630, Japan filterability of sludge from the DCPD method were better than those of the conventional method. The release of fluoride from the DCPD sludge was below the levels stipulated by Japanese soil pollution regulations. Consequently, the sludge was considered unlikely to cause soil pollution, thereby facilitating landfill management. We concluded that DCPD can be used effectively to treat fluoride-containing wastewater and that the resulting sludge is unlikely to cause environmental damage.

Keywords Fluoride $\cdot$ Water treatment $\cdot$ Dicalcium phosphate $\cdot$ Sludge properties

\section{Introduction}

Fluoride-containing wastewater results from many chemical processes, particularly those involved in the semiconductor, plating, and metal industries. Such wastewater can contain thousands of milligrams per liter of fluoride, most of which must be recycled [31]. Calcium fluoride $\left(\mathrm{CaF}_{2}\right)$ is a natural source of fluoride. Consequently, it is desirable to recover most of the fluoride in wastewater as $\mathrm{CaF}_{2}$, and this is done in many fluoride-based industries in Japan. In the recovery of fluoride as $\mathrm{CaF}_{2}$, the recovered $\mathrm{CaF}_{2}$ often contain calcium carbonate $\left(\mathrm{CaCO}_{3}\right)$ because of reactions between the added calcium salt and carbon dioxide in the atmosphere [24]. We previously developed a fluoride-recovery method to form pure $\mathrm{CaF}_{2}$ using anaerobic conditions that minimized wastewater contact with the atmosphere [24]. However, wastewater from this $\mathrm{CaF}_{2}$ recovery process still contained $20-30 \mathrm{mg} \mathrm{L}^{-1}$ of fluoride ions. Effluent from the conventional treatment of fluoridecontaining wastewater contains similar levels of fluoride. The Japanese environmental standard for fluoride in 
effluent is set at $8 \mathrm{mg} \mathrm{L}^{-1}$ [16], but many local governments set even stricter standards for fluoride. Consequently, the development of high-performance treatments to remove fluoride from wastewater is necessary. Much research has been undertaken to investigate novel techniques to remove fluoride ions from water. Currently, aluminum coprecipitation is generally applied for the fluoride treatment of effluent [20]. However, this process generates large amounts of wet sludge, which requires disposal as landfill. An alternative approach would be to use hydroxyapatite $\left[\mathrm{HAp}, \mathrm{Ca}_{10}\left(\mathrm{PO}_{4}\right)_{6}(\mathrm{OH})_{2}\right]$ as a possible fluoride adsorbent. Via ion exchange and/or dissolutionprecipitation reactions, $\mathrm{HAp}$ is able to remove fluoride to form stable fluorapatite [FAp, $\left.\mathrm{Ca}_{10}\left(\mathrm{PO}_{4}\right)_{6} \mathrm{~F}_{2}\right]$ [23], and can be obtained as bone char from food waste. FAp and HAp is stable in neutral $\mathrm{pH}$ range [6]. However, the adsorption capacity of HAp for ionic fluoride is only a few milligrams per gram when fluoride must be removed to levels around 5-8 mg L ${ }^{-1}[14,15]$. Consequently, large amounts of HAp would be required for water treatment, and large amounts of FAp-containing sludge would be generated as a result.

In the wastewater treatment process, important factors include not only the removal efficiency of the pollutant but also the generation of secondary waste products such as harmful sludge [11]. Many researchers focus solely on improving removal efficiencies, but we are also concerned with controlling secondary emissions from wastewater treatment [18]. Because of limited landfill availability, reducing the amount of sludge generated during wastewater treatment is a major consideration. The settleability and filterability of the sludge are also important factors because they directly affect the throughput and operating costs of treatment plants [31]. The particle size of the sludge obtained from wastewater treatment reflects its filterability and directly influences operation and maintenance costs. The FAp particles obtained from aqueous solution are generally under $1 \mu \mathrm{m}$ in range and are difficult to separate by normal filtration [12]. Some research has evaluated how the characteristics of sludge generated from wastewater treatment impinge on operating costs [4]. The release of pollutants from sludge is also an important factor because the treatment of landfill leachate is required if pollutants are present. During the treatment of landfill leachate, large amounts of sludge will again be generated [22]. This phenomenon directly affects the operation and costs of landfill management [31].

We have previously investigated various applications of calcium phosphate, especially dicalcium diphosphate dihydrate (DCPD, $\mathrm{CaHPO}_{4} \cdot 2 \mathrm{H}_{2} \mathrm{O}$ ), to immobilize fluoride by taking it up from the environment [30]. DCPD reacts with fluoride ions to form stable FAp. This reaction has been investigated in the field of dental science $[1,5]$. In our earlier studies, it was suggested that DCPD does not react with fluoride directly but instead, in an initial phase, forms nanoscale precursor particles on the surface of DCPD [25]. After formation of the nanoscale precursors, DCPD reacts quickly with fluoride to form FAp. And precursor-induced DCPD is easily prepared by mixing DCPD with water [27]. It can then be applied to immobilize fluoride in industrial waste [26].

In this study, we used DCPD to treat wastewater and/or effluent containing $20-30 \mathrm{mg} \mathrm{L}^{-1}$ of fluoride. DCPD reacts with fluoride ions over a wide $\mathrm{pH}$ range, i.e., from $\mathrm{pH} 3$ to 11, without requiring any $\mathrm{pH}$ adjustment [28]. Consequently, using DCPD to treat fluoride-containing wastewater requires no additional chemicals, making DCPD is one of the best candidates for the treatment of fluoride in wastewater.

Phosphorous and phosphate are important natural resources found in countries such as Morocco and Tunisia [2]. These resources are mainly used in agricultural applications such as the production of fertilizer [3]. Expansion of the application of phosphate to water treatment would be beneficial to the economic and industrial development of these countries.

In this study, the efficiency of fluoride treatment and the properties of the sludge resulting from the removal of fluoride from wastewater using DCPD were investigated. Experiments on the conventional aluminum coprecipitation method were also performed to allow a comparative assessment of the overall practicality of the DCPD process. Our findings indicated that DCPD can effectively remove fluoride from wastewater with low secondary emissions and reduced sludge-handling costs.

\section{Materials and methods}

\section{Materials and reagents}

The DCPD used in this study was a by-product of the gelatin industry. To improve the reactivity of DCPD toward fluoride ions, DCPD was mixed with warm water (about $40{ }^{\circ} \mathrm{C}$ ) to induce nanoscale precursor particles on its surface [27]. The resulting nano-surfaced DCPD (NSDCPD) was used in this study. Specific surface area of the NS-DCPD was $18.6 \mathrm{~m}^{3} \mathrm{~g}^{-1}$. Effluent from the fluoride treatment unit for scrubber water in a waste incineration plant was used as fluoride-containing wastewater. The fluoride concentration of this wastewater was around $30 \mathrm{mg} \mathrm{L}^{-1}$, and $\mathrm{pH}$ was 9.4. A reference fluoride solution was prepared by dissolving sodium fluoride in pure water. The pure water used in this study was prepared by using a Milli-Q water purifier (A10 Academic, Merck Millipore, Darmstadt, Germany). 


\section{Experimental method}

Change of particle size distribution of DCPD after reaction with fluoride

Two hundred and fifty milliliters of reference fluoride solution containing $20 \mathrm{mg} \mathrm{L}^{-1}$ of fluoride and $0.50 \mathrm{~g}$ of NS-DCPD were added to a glass reactor and mixed using a propeller mixer for $1 \mathrm{~h}$. The mixing speed and treatment temperature were $200 \mathrm{rpm}$ and $30^{\circ} \mathrm{C}$. After $1 \mathrm{~h}$, the solid phase was collected by vacuum filtration, and the particle size distribution was assessed by a laser diffraction particle size analyzer (SALD-2200, Shimadzu, Kyoto, Japan). For comparison, the particle size distribution of NS-DCPD before treatment was also analyzed.

\section{Wastewater treatment}

Fifty milliliters of fluoride-containing wastewater and various amounts of NS-DCPD were placed in a glass reactor and mixed for $1 \mathrm{~h}$ using a magnetic stirrer and stirring bar. No flocculant chemicals to enhance precipitation of the sludge were added. After treatment, the sludge was separated by vacuum filtration and weighed. The fluoride concentration of treated wastewater was analyzed using a fluoride ion selective electrode (ISE, ThermoORION 9409BN, Thermo Fisher Scientific, Waltham, MA USA) connected to an ion meter (SevenMulti, MettlerToledo, Greifensee, Switzerland). Water treatment was also carried out using the conventional aluminum coprecipitation method. Various amounts of aluminum sulfate solution $(50 \mathrm{w} / \mathrm{v} \%)$ were added to the wastewater, and $\mathrm{pH}$ of the solution was adjusted to around 7 to precipitate aluminum hydroxide by adding calcium hydroxide slurry. The methods used for collection and characterizations of the sludge and treated water were the same as those described above.

\section{Characterization of sludge}

Crystal phase of sludge obtained from wastewater treatment was analyzed by powder X-ray diffractometer (MiniFlex, Rigaku, Toykyo, Japan). Wavelength of X-ray used in this measurement was $\mathrm{Cu} \mathrm{K} \alpha(0.154 \mathrm{~nm})$, and power is $450 \mathrm{~W}(15 \mathrm{kV}$ and $30 \mathrm{~mA})$.

The settleability of sludge obtained from wastewater treatment was measured using the 30-min settling test (SV30 test), which is widely used for measuring the settleability of sewage activated sludge. Briefly, $100 \mathrm{~mL}$ of well-mixed sludge and treated water was transferred to a measuring cylinder and allowed to stand for $30 \mathrm{~min}$. The volume of the precipitated sludge was then measured. A schematic of the SV30 method is shown in Fig. 1. The

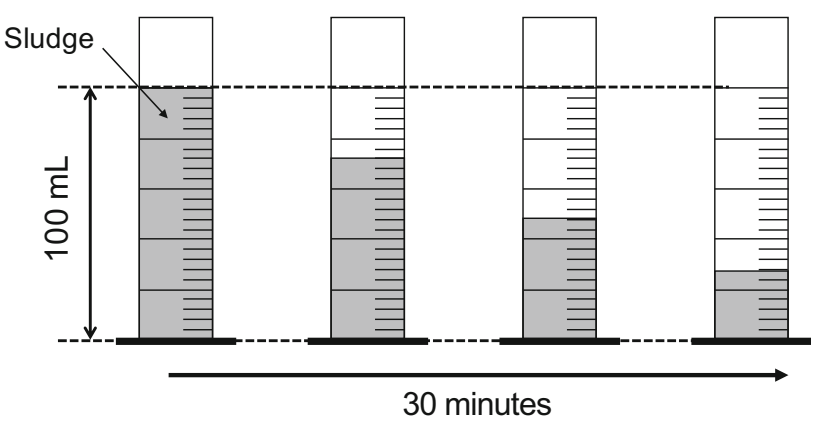

Fig. 1 Schematic of the measurement of sludge settleability in the SV30 test

filterability was measured using filter paper (Type 5B, Toyo Roshi Kaisha, Tokyo, Japan, Minimum collectable particle size is $4 \mu \mathrm{m}$.). Fifty milliliters of treated water/sludge slurry were poured into fluted filter paper, and the volume of filtered water was measured after $5 \mathrm{~min}$. This measurement was carried out by gravity filtration.

The elution of fluoride from the sludge was analyzed using the method stipulated by the Japanese soil pollution regulations [17]. Then, $1 \mathrm{~g}$ of sludge was mixed with $10 \mathrm{~mL}$ of purified water and shaken for $6 \mathrm{~h}$ at $200 \mathrm{rpm}$ in a reciprocal shaker (NR-1, TAITEC, Tokyo, Japan). After shaking, the liquid phase was separated by ultracentrifugation (CF-15R, Hitachi, Tokyo, Japan) at $870 \mathrm{~g}(3000 \mathrm{rpm})$ for $20 \mathrm{~min}$ and then filtered using a 0.45 $\mu \mathrm{m}$ membrane filter. The fluoride concentration in the filtrate was measured by an ISE and ion meter.

\section{Results and discussion}

\section{Change of particle size after reaction of DCPD with fluoride}

Change of particle size distribution of NS-DCPD was observed after reaction with fluoride solution followed the method described in "Change of particle size distribution of DCPD after reaction with fluoride". Figure 2 shows the particle size distribution of NS-DCPD before the reaction with fluoride ions in aqueous solution and that of the resulting sludge. Particle size of DCPD was around $150 \mu \mathrm{m}$ before reaction with fluoride ion. The particle size distribution of DCPD was not greatly changed after the reaction. In a previous study, we suggested that the reaction of DCPD with fluoride ions is not a dissolution-precipitation reaction but a heterogeneous reaction on the surface of DCPD $[19,25]$. The minor changes in the particle size of DCPD after reacting with fluoride was a result of the characteristics of this heterogeneous reaction. In a previous study, we developed a method for controlling the particle shape of DCPD by addition of acetic acid [10] or adjusting 


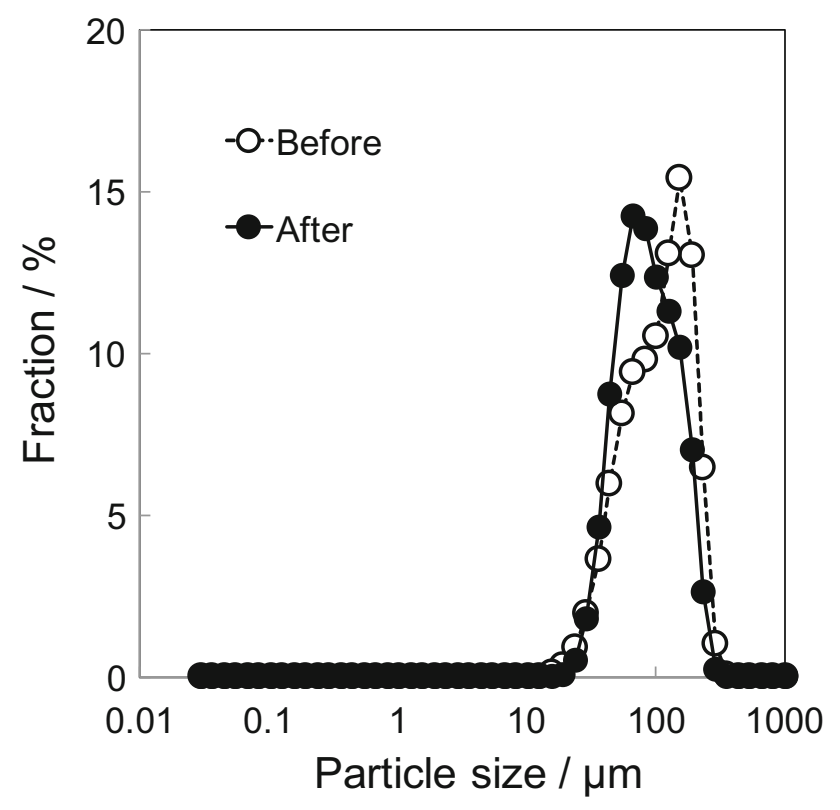

Fig. 2 Change in particle size distribution of DCPD before and after the reaction with fluoride ions in a reference fluoride solution containing $20 \mathrm{mg} \mathrm{L}^{-1}$ of fluoride

the $\mathrm{pH}$ and reactant concentrations in a simplified aqueous solution process [29]. Consequently, the particle size and filterability of the sludge resulting from wastewater treatment with DCPD can likely be controlled by adjusting the morphology of DCPD during its manufacture.

\section{Efficiency of fluoride removal and sludge generation}

Crystal phase of obtained sludge after treatment of wastewater by NS-DCPD was analyzed by powder X-ray diffraction (XRD). Figure 3 shows powder XRD patterns of NS-DCPD before and after treatment of wastewater. No peaks of DCPD were observed in XRD patterns after reaction in this figure, and all of the peaks were identified by peaks of FAp. From this result, NS-DCPD was successfully transferred to FAp by reaction with fluoride in wastewater.

The efficiency of pollutant removal is a major factor during water treatment. To investigate the efficiency of fluoride removal, different amounts of NS-DCPD were added to fluoride-containing wastewater, and the mixture was allowed to react for $1 \mathrm{~h}$. Aluminum sulfate solution $(50 \% \mathrm{w} / \mathrm{v})$ and calcium hydroxide slurry were also applied as the conventional coprecipitation fluoride treatment method for wastewater.

The fluoride concentrations in the samples of treated water are shown in Fig. 4. Both the DCPD and aluminum coprecipitation methods successfully decreased the fluoride concentration in the wastewater to an extent determined by the amounts of chemicals added. To reach levels of fluoride

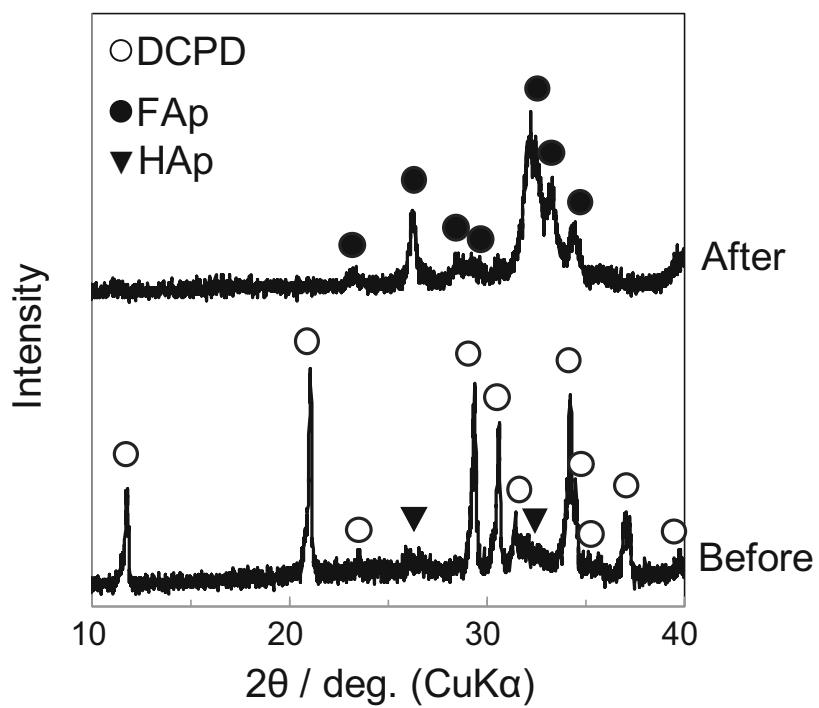

Fig. 3 Powder X-ray patterns of NS-DCPD before and after treatment of wastewater

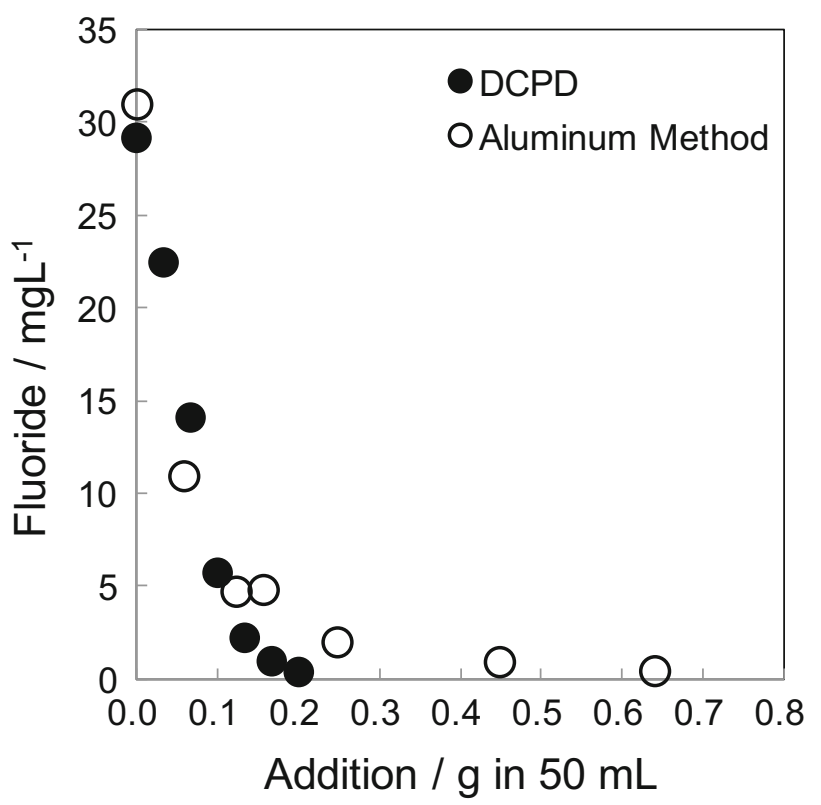

Fig. 4 Treatment efficiency of fluoride in wastewater as a function of the added amounts of water treatment chemicals. The $X$-axis shows the amount of added chemicals (NS-DCPD in the DCPD method, and aluminum sulfate and calcium hydroxide in the aluminum method)

below $5 \mathrm{mg} \mathrm{L}^{-1}$ in the treated water, larger amounts of added chemicals were required in the conventional aluminum method. This finding suggests that using the DCPD process would reduce the amount of chemicals required for water treatment. The DCPD process has the added advantage that only one chemical is added to wastewater.

The amount of pollutant removed for a given weight of added chemicals is an important operational parameter in water treatment. The data shown in Fig. 4 were used to 


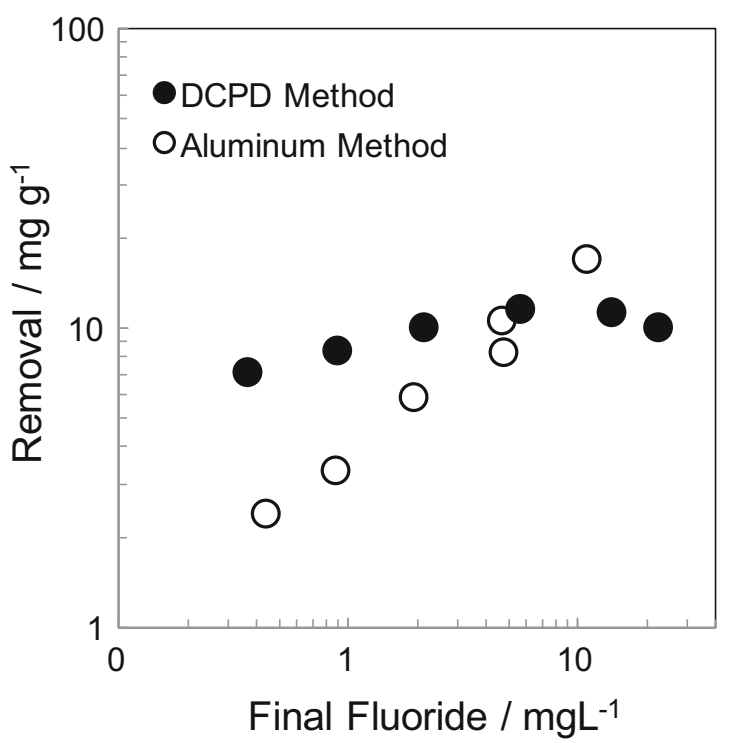

Fig. 5 Specific removal amount of fluoride per unit mass of added chemicals as a function of the final fluoride concentration

calculate the overall specific removal of fluoride ions versus the final concentration of fluoride in the treated wastewater, as shown in Fig. 5. This figure shows a double logarithmic plot similar to that used for Freundlich adsorption isotherms. The specific removal amount for the aluminum method showed a linear relationship on the Freundlich plot. In the aluminum coprecipitation method, aluminum hydroxide precipitates and adsorbs fluoride ions. The straight line exhibited by the aluminum method is a typical characteristic of a Freundlich adsorption curve and supports the known removal mechanism of fluoride ions by precipitated aluminum hydroxide [8]. Generally, the specific adsorption amount of the adsorbent decreases at low equilibrium pollutant concentrations in the solution. To reduce the fluoride concentration in wastewater to around $5 \mathrm{mg} \mathrm{L}^{-1}$, the adsorption capacity of carbonate materials such as bone char is $1-4 \mathrm{mg} \mathrm{g}^{-1}$, whereas, for more expensive polymeric resin, the adsorption capacity is $7 \mathrm{mg} \mathrm{g}^{-1}[14,15]$. Figure 5 shows that the specific removal amount for the aluminum method falls to a few milligrams per gram when the final fluoride concentration is a few milligrams per liter. In contrast, the specific removal amount of fluoride by DCPD was as high as $8 \mathrm{mg} \mathrm{g}^{-1}$ even when the final fluoride concentration was less than $1 \mathrm{mg} \mathrm{L}^{-1}$. This value was greater than that for expensive polymeric resin, as well as that for the conventional aluminum method. Consequently, DCPD appears to be very efficient at removing fluoride from wastewater. The amount of sludge generated is an important factor in the economic efficiency of wastewater treatment because of costs associated with transporting and disposing of sludge in landfills. The amounts of sludge generated from the

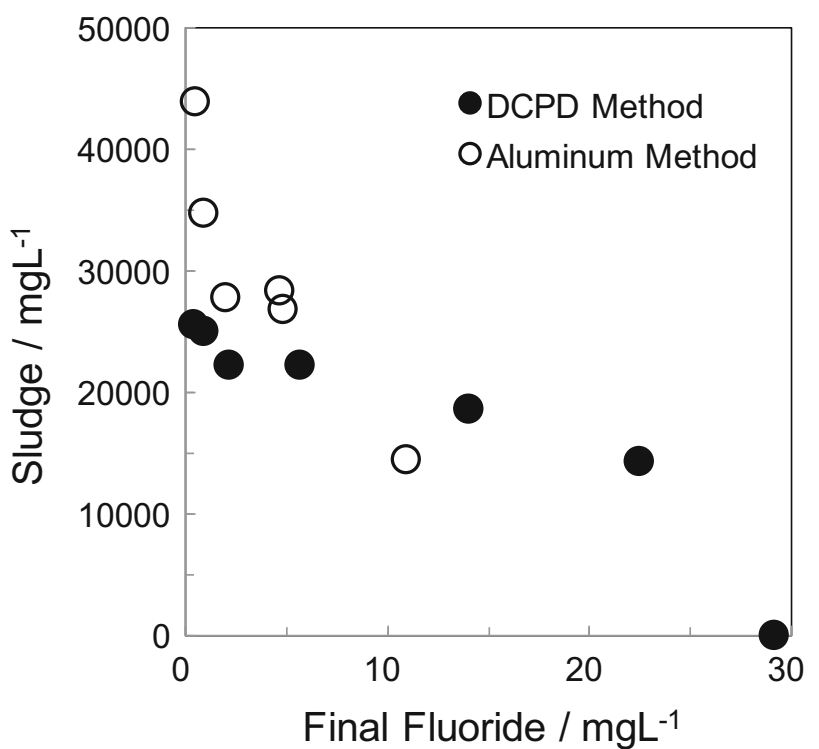

Fig. 6 Amount of sludge generated by the treatment of fluoride in wastewater using the conventional aluminum method and the DCPD method. Sludge was collected by simple filtration without drying. The $X$-axis shows the concentration of fluoride ions in solution after wastewater treatment

DCPD and conventional aluminum processes were measured by simple filtration without drying. The results are shown in Fig. 6. The amount of sludge generated by the aluminum method increased rapidly when the final fluoride concentration was below $5 \mathrm{mg} \mathrm{L}^{-1}$. However, the amount of sludge generated by the DCPD method was less than that generated by the conventional method when the final fluoride concentration was below about $7 \mathrm{mg} \mathrm{L}^{-1}$. Therefore, it appears that application of the DCPD method would reduce the amount of sludge generated when removing fluoride from wastewater.

\section{Properties of the sludge generated when treating fluoride-containing wastewater}

The settleability and filterability of sludge are important parameters because they directly affect plant throughput and operating costs. Sludge with poor settleability requires increased precipitation times and may need additional flocculants. In both cases, the operating costs for water treatment will increase. Therefore, the rapid settlement of sludge is important for economical wastewater treatment. The settleability of the sludge generated in the current experiments was analyzed using the SV30 method shown in Fig. 1. Figure 7 shows the results of SV30 tests on sludge from the DCPD and conventional aluminum methods. The sludge from the DCPD method was completely precipitated within $10 \mathrm{~min}$, whereas the sludge from the conventional aluminum method was not fully settled after 


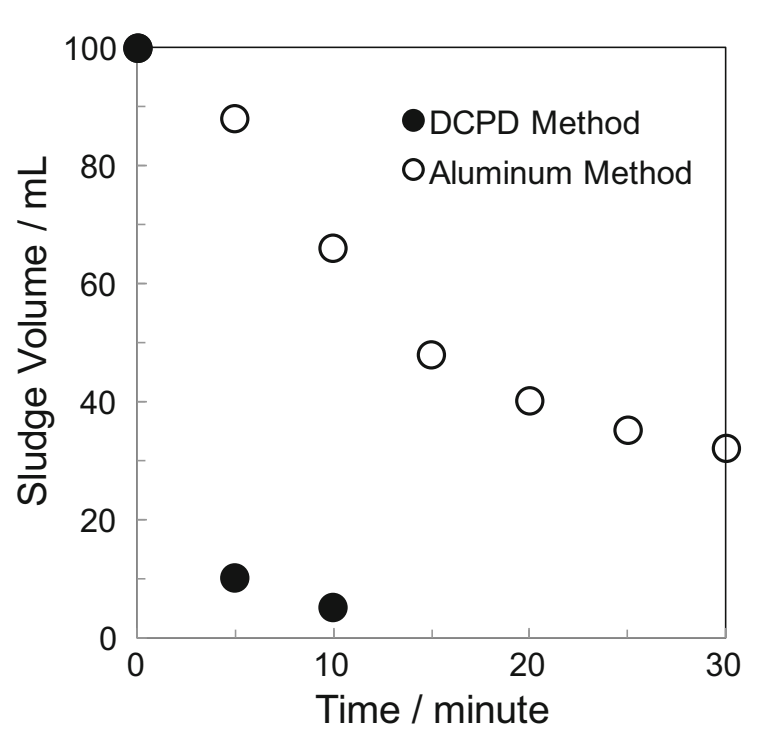

Fig. 7 Settleability of sludge generated by the treatment of fluoride in wastewater using the conventional aluminum method and the DCPD method

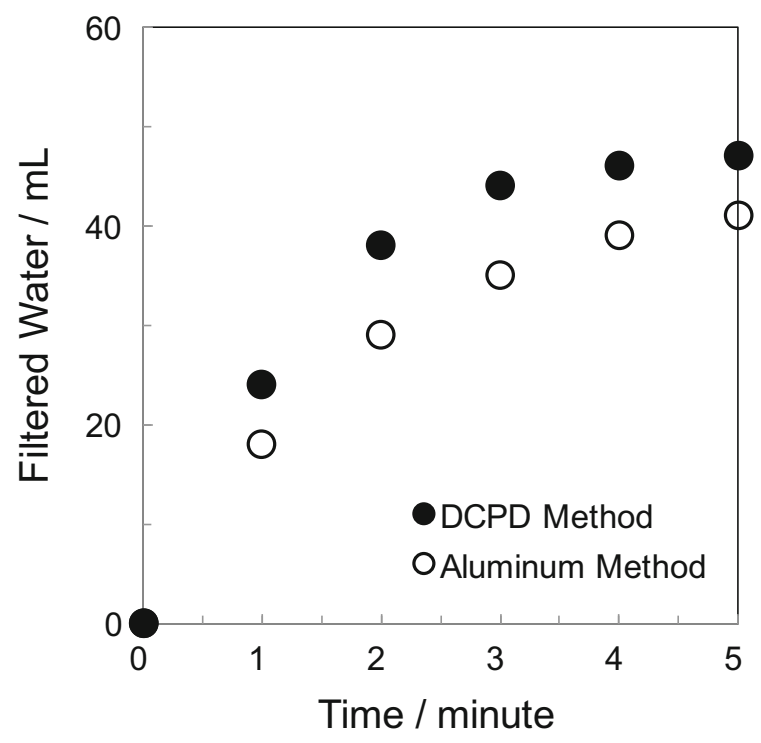

Fig. 8 Filterability of sludge obtained from the treatment of fluoride in wastewater using the conventional aluminum method and the DCPD method

the $30 \mathrm{~min}$ of the test had elapsed. DCPD sludge evidently settles more quickly than aluminum sludge and does not require additional flocculants.

The filterability of the sludge was assessed by measuring the volume of water filtered from the sludge using filter paper (Fig. 8). The volume of filtered water from conventional aluminum slurry reached a plateau of about $80 \%$ of the initial slurry volume. Fine particles in slurry clog the filter paper and limit the filterability. The clogging of filters reduces their lifetime and thereby increases
Table 1 Eluted fluoride concentration from sludge obtained by the DCPD and conventional aluminum methods

\begin{tabular}{ll}
\hline Water treatment method & Fluoride in leachate $\left(\mathrm{mg} \mathrm{L}^{-1}\right)$ \\
\hline Conventional aluminum & 0.95 \\
DCPD & 0.60 \\
\hline
\end{tabular}

Japanese soil pollution standard $0.8 \mathrm{mg} \mathrm{L}^{-1}$

costs. Sludge from the conventional aluminum method seems likely to cause such problems because of its low filterability. In contrast, most of the water in the slurry from the DCPD method was separated within $5 \mathrm{~min}$. As described in "Change of particle size after reaction of DCPD with fluoride", the particle size of the DCPD was not greatly changed by the reaction with fluoride ions. The initial particle characteristics of the DCPD are therefore responsible for the short filtration time of the DCPD slurry. Consequently, adoption of the DCPD method should result in easy filtration during wastewater treatment.

The release of pollutants from sludge causes difficulty with respect to landfill management [22]. If the release of pollutants from sludge is within the environmental standards for soil pollution, then the sludge can be recycled as a roadbed material. Consequently, the elution of fluoride ions from the sludge generated in our experiments was analyzed. Table 1 shows the concentrations of eluted fluoride in leachate from DCPD sludge and from conventional aluminum sludge. The release of fluoride ions from DCPD sludge was within the environmental standard for soil pollution in Japan, i.e., $0.8 \mathrm{mg} \mathrm{L}^{-1}$ [17], whereas that for aluminum sludge was not.

\section{Usability of DCPD for treatment of fluoride- containing wastewater}

The usability of DCPD for fluoride-containing wastewater treatment was estimated in comparison with that of the conventional aluminum coprecipitation method (Table 2). The values given in Table 2 are for $90 \%$ fluoride removal from wastewater, i.e., from 30 to $3 \mathrm{mg} \mathrm{L}^{-1}$. All parameters of the DCPD method were better than those of the conventional method. In particular, the settleability and filterability of DCPD sludge were excellent. For effective water treatment, not only is the pollutant removal efficiency important, but the settleability and filterability are also important factors because they directly affect plant throughput and operating costs. This table also describes the comparison of the costs of water treatment. From this result, usage of DCPD is $20-30 \%$ of cheaper than conventional aluminum coprecipitation process. Our findings indicate that the application of DCPD as a novel treatment 
Table 2 Comparison of the DCPD and conventional aluminum methods for a fluoride reduction from 30 to $3 \mathrm{mg} \mathrm{L}^{-1}$

\begin{tabular}{lll}
\hline & Aluminum method & DCPD method \\
\hline Addition of chemicals & Aluminum salt, Ca(OH) $)_{2} 4 \mathrm{~kg} \mathrm{~m}^{-3}$ & DCPD only $2.4 \mathrm{~kg} \mathrm{~m}^{-3}$ \\
Adjustment of $\mathrm{pH}$ value & Required & Not required \\
Removal capacity & $6 \mathrm{mg} \mathrm{g}^{-1}$ & $12 \mathrm{mg} \mathrm{g}^{-1}$ \\
Sludge amount & $30 \mathrm{~kg} \mathrm{~m}^{-3}$ & $24 \mathrm{~kg} \mathrm{~m}^{-3}$ \\
Settleability after $30 \mathrm{~min}$ & $40 \mathrm{vol} \%$ & $<5 \mathrm{vol} \%$ \\
Filterability after 5 min & $82 \mathrm{vol} \%$ & $94 \mathrm{vol} \%$ \\
Elution of fluoride from sludge & $>0.8 \mathrm{mg} \mathrm{L}^{-1}$ & $<0.8 \mathrm{mg} \mathrm{L}^{-1}$ \\
Total cost & $970 \mathrm{JPY} \mathrm{m}^{-3}$ & $720 \mathrm{JPY} \mathrm{m}^{-3}$ \\
\hline
\end{tabular}

for fluoride-containing wastewater would likely be efficient and cost-effective.

\section{Conclusions}

The properties of sludge obtained from the removal of fluoride in wastewater using DCPD were as follows:

1. The particle size distribution of unused DCPD was not greatly different to that of the sludge resulting from the reaction with fluoride ions.

2. Fluoride in the wastewater was successfully reduced to levels below the Japanese standard for wastewater treatment $\left(8 \mathrm{mg} \mathrm{L}^{-1}\right)$.

3. For final fluoride levels below about $7 \mathrm{mg} \mathrm{L}^{-1}$, the amount of sludge produced by the DCPD method was less than that produced by the conventional aluminum method.

4. The settleability and filterability of DCPD sludge was better than those of sludge from the conventional method.

5. The release of fluoride from the DCPD sludge was below the Japanese environmental standard for soil pollution $\left(0.8 \mathrm{mg} \mathrm{L}^{-1}\right)$.

Because DCPD could remove fluoride from water to achieve final concentrations below $1 \mathrm{mg} \mathrm{L}^{-1}$ while maintaining a high specific removal capacity, its application may be suitable not only for wastewater but also for surface and groundwater polluted with fluoride. Fluoride in the environment is a serious problem worldwide. Environmental fluoride-related health problems are faced in Tunisia [9, 13], Turkey [21], and more than 20 other countries around the world [7]. The application of DCPD to tackle polluted surface and groundwater could be an interesting possibility in the near future. Progress in the novel application of DCPD to the treatment of fluoridecontaining wastewater could prove to be an important factor in the development of diverse and robust phosphate industries in North African countries. Development of novel uses for phosphate could promote economic and industrial development in North African countries with important phosphate reserves.

Acknowledgments The authors appreciate the experimental support given by Mr. Daiki Takehara, Mr. Shunki Muroyama, Ms. Mana Futakuchi, and Ms. Yukina Chujo (National Institute of Technology, Toyama College). The authors are also grateful for productive discussions with, and advice from, Mr. Yoshiki Shimizu (Daikin Industries, Ltd.) and Mr. Takumi Fujita (Chiyoda Ute Co., Ltd.). This research was partially support by a Grant-in-Aid for Scientific Research (B) from the Japan Society for the Promotion of Science and a research grant from The Academic Consociation of Environmental Safety and Waste Management, Japan.

\section{Compliance with ethical standards}

Conflicts of interest All of the authors have declared no conflicts of interest.

\section{References}

1. Chow LC, Brown WE (1973) Reaction of dicalcium phosphate dihydrate with fluoride. J Dent Res 52:1220-1227

2. Cisse L, Mrabet T (2004) World phosphate production: overview and prospects. Phos Res Bull 15:21-25

3. Corbridge DEC (2013) Applications of phosphorous compunds. In: Corbridge DEC (ed) Phosphorous, 6th edn. CRC Press, Boca Raton, pp 1025-1038

4. Drouichea N, Ghaffourb N, Lounicic H, Mameric N, Maallemia A, Mahmoudid H (2008) Electrochemical treatment of chemical mechanical polishing wastewater: removal of fluoride-sludge characteristics-operating cost. Desalination 223:134-142

5. Duff EJ (1970) Orthophosphates-I. Formation of apatites from calcium phosphates in potassium fluoride solutions. J Inorg Nucl Chem 32:3707-3708

6. Eliot JC (1994) General chemistry of the calcium orthophosphates. In: Eliot JC (ed) Structure and chemistry of the apatite and other calcium phosphates. Elsevier, Oxford, p 19

7. Fawell J, Bailey K, Chilton J, Dahi E, Fewtrell L, Magara Y (2006) Fluoride in drinking water. IWA Publishing, London

8. Ganvir V, Das K (2011) Removal of fluoride from drinking water using aluminum hydroxide coated rice husk ash. J Hazard Mater 185:1287-1294

9. Guissouma W, Tarhouni J (2015) Fluoride in Tunisian drinking tap water. J Water Resour Protect 7:860-870

10. Hamai R, Toshima T, Tafu M, Masutani T, Chohji T (2012) Effect of anions on morphology control of brushite particles. Key Eng Mater 529-530:55-60 
11. Kanazawa T (1982) Environmental aspects of sludge byproducts in the system $\mathrm{Ca}-\mathrm{F}-\mathrm{PO}_{4}$. J Soc Inorg Mater Jpn (Gypsum \& Lime) 179:194-198

12. Majima T, Takatsuki H (1989) Enhanced removal of fluorine from wastewater by crystallization and co-precipitation processes. J Soc Inorg Mater Jpn (Gypsum \& Lime) 221:210-216

13. Maatouk F, Jmour B, Ghedira K, Argoubi K, Abid A (1998) Dental fluorosis in Kairouan, Tunisia. Dent News 5(1):17-19

14. Medellin-Castillo NA, Leyva-Ramos R, Ocampo-Perez R, Garcia de la Cruz R, Aragon-Pina A, Martinez-Rosales J, GuerreroCoronado R, Fuentes-Rubio L (2007) Adsorption of fluoride from water solution on bone char. Ind Eng Chem Res 46:9205-9212

15. Medellin-Castillo N, Leyva-Ramos R, Padilla-Ortega E, Ocampo Perez R, Flores-Cano JV, Berber-Mendoza MS (2014) Adsorption capacity of bone char for removing fluoride from water solution. Role of hydroxyapatite content, adsorption mechanism and competing anions. J Ind Eng Chem 20:4014-4021

16. Ministry of the Environment (MOE), Japan (1996) Water pollution control law (Japanese Law: Act No. 58)

17. Ministry of the Environment (MOE), Japan (2002) Soil Contamination Countermeasures Act (Japanese Law: Act No. 53)

18. Mohapatra M, Anand S, Mishra BK, Giles DE, Singh P (2009) Review of fluoride removal from drinking water. J Environ Manag 91:67-77

19. Monma H, Ueno S (1981) Uptake of fluoride ion by octacalcium phosphate and related calcium salts. J Soc Inorg Mater Jpn (Gypsum \& Lime) 172:101-107

20. O'Brien WJ (1983) Control options for nitrates and fluorides. Water Eng Manag 130:36-38

21. Oruc N (2008) Occurrence and problems of high fluoride waters in Turkey: an overview. Environ Geochem Health 30:315-323
22. Renou S, Givaudan J-G, Poulain S, Dirassouyan F, Moulin P (2008) Landfill leachate treatment: review and opportunity. J Hazard Mater 150:468-493

23. Sternitzke V, Kaegi R, Audinot J-N, Lewin E, Hering JG, Johnson CA (2012) Uptake of fluoride from aqueous solution on nano-sized hydroxyapatite: examination of a fluoridated surface layer. Environ Sci Technol 46:802-809

24. Tafu M, Chohji T (2003) Minimum-emission-oriented method for calcium fluoride for high-quality treatment of wastewater containing fluoride ion. J Jpn Soc Water Environ 26:33-38

25. Tafu M, Chohji T (2005) Reaction of calcium hydrogenphosphate dihydrate (DCPD) with a solution containing a small amount of fluoride. J Ceram Soc Jpn 113:363-367

26. Tafu M, Chohji T (2006) Reaction between calcium phosphate and fluoride in phosphogypsum. J Eur Ceram Soc 26:767-770

27. Tafu M, Chohji T, Morioka I, Hiwasa M, Nakano H, Fujita T (2010) Stabilization of fluoride in waste gypsum by using surface-modified calcium phosphate particle. Trans Mater Res Soc Jpn 35:377-380

28. Tafu M, Chohji T, Korenaga T (2010) Treatment of fluoride in wastewater and waste gypsum board based on nano-surface reaction of calcium phosphate. J Environ Safety 1(2):33-39

29. Toshima T, Hamai R, Tafu M, Takemura Y, Fujita S, Chohji T, Tanda S, Li S, Qin G (2014) Morphology control of brushite prepared by aqueous solution synthesis. J Asian Ceram Soc 2:52-56

30. Tafu M, Manaka A (2015) Immobilization of fluoride and heavymetals in polluted soil. In: Hasegawa $\mathrm{H}$ et al (eds) Environmental remediation technologies for metal-contaminated soils. Springer, Tokyo, pp 147-159

31. Toyoda A, Taira T (2000) A new method for treating fluorine wastewater to reduce sludge and running costs. IEEE Trans Semicond Manuf 13:305-309 